Jurnal Ilmiah Matematika dan Pendidikan Matematika (JMP)

Vol. 12 No. 1, Juni 2020, hal. 47-57

ISSN (Cetak) : 2085-1456; ISSN (Online) : 2550-0422

\title{
PELABELAN ANTI AJAIB JARAK PADA \\ SUATU GRAF PETERSEN DIPERUMUM
}

\author{
Dian Eka Wijayanti \\ Prodi Matematika, FAST, Universitas Ahmad Dahlan, Yogyakarta \\ dian@math.uad.ac.id \\ Aris Thobirin \\ Prodi Matematika, FAST, Universitas Ahmad Dahlan, Yogyakarta
}

\begin{abstract}
One type of graph labeling is distance labeling which is labelled a graph based on the distance between the vertices. This distance labeling is called distance magic labeling (magic labeling distance) if each vertex has the same distance labeling weights. The distance labeling is called distance antimagic labeling if each vertex has different distance labeling weights, formed an arithmetic progressive $a, a+d, a+2 d, \ldots$ ,$a+(n-1) d$, where $d>0$. This paper discusses the anti-magic labeling distance on generalized Petersen graph, denote $G=P(n, m)$ with $n \geq 3,1 \leq m<n / 2$, a regular graph with degree 3 that has $2 n$ vertices and $3 n$ edges. More over, this paper also discuss about $(a, d)$-distance anti-magic labeling on generalized Petersen graph.
\end{abstract}

Keywords: generalized Petersen graph, distance labeling, distance antimagic labeling

\begin{abstract}
ABSTRAK. Salah satu jenis pelabelan pada graf adalah pelabelan jarak yang merupakan pelabelan graf berdasarkan jarak antara titik-titiknya. Pelabelan jarak ini disebut distance magic labeling (pelabelan ajaib jarak) jika setiap titik mempunyai bobot pelabelan jarak yang sama. Pelabelan jarak ini disebut $(a, d)$-distance antimagic labeling (pelabelan $(a, d)$-anti ajaib jarak) jika setiap titik mempunyai bobot pelabelan jarak yang berbeda, membentuk suatu deret aritmatika progresif $a, a+d, a+2 d, \ldots, a+(n-1) d$, dengan nilai $d>0$. Tulisan ini membahas tentang pelabelan anti ajaib jarak pada graf petersen diperumum yaitu $G=P(n, m)$ dengan $n \geq 3,1 \leq m<n / 2$ suatu graf teratur berderajat 3 yang mempunyai $2 n$ titik dan $3 n$ sisi. Lebih lanjut, tulisan ini juga membahas tentang pelabelan $(a, d)$-anti ajaib jarak pada suatu graf petersen diperumum.
\end{abstract}

Kata Kunci: graf petersen diperumum, pelabelan jarak, pelabelan anti ajaib jarak

\section{PENDAHULUAN}

Secara umum, pelabelan graf dapat didefinisikan berdasarkan distance (jarak) antara titik-titiknya. Domain dari distance labeling (pelabelan jarak) adalah himpunan semua titik $v$ di $G$ dan kodomainnya adalah $\{1,2, \ldots, p\}$ dengan $p$ adalah banyaknya titik pada graf $G$. Griggs pada tahun 1992 mendefinisikan suatu pelabelan jarak $\operatorname{Ld}(2,1)$ sebagai suatu label titik-titik berjarak 1 dan 2 yang harus berbeda. Konsep pelabelan jarak dikemukakan kembali oleh Miller pada 
tahun 2003 dengan nama 1-vertex labeling yang mendefinisikan bobot setiap titik $x$ dalam graf $G$ sebagai jumlah label dari titik-titik yang memiliki jarak 1 dari $x$ atau dengan kata lain bertetangga dengan $x$. Lebih lanjut, jika semua titik di $G$ mempunyai bobot yang sama, katakan $c$, maka pelabelan ini dinamakan 1-vertexmagic vertex labeling dan konstanta $c$ dinamakan sebagai magic konstan. Pada tahun 2008, Beena membahas tentang $\Sigma$-labeling yang sebenarnya adalah 1 vertex-magic vertex labeling dan $\Sigma$ '-labeling yang merupakan $\{0,1\}$-vertex-magic vertex labeling. Oneal pada tahun 2013 menunjukkan bahwa magic konstan ini unik untuk setiap pelabelan jarak pada graf.

Suatu pelabelan jarak dikatakan pelabelan $(a, d)$-anti ajaib jarak jika himpunan dari bobot tiap titiknya membentuk himpunan aritmatika yang progresif $\{a, a+d, a+2 d, \ldots, a+(n-1) d\}$. Graf yang mempunyai pelabelan $(a, d)$-anti ajaib jarak dinamakan graf $(a, d)$-anti ajaib jarak. Arumugam (2012) menyajikan beberapa hasil pelabelan $(a, d)$-anti ajaib jarak ini dalam penelitiannya pada tahun 2012. Dia juga membuktikan bahwa disjoint copies dari hypercube Q3 adalah graf $(a, 1)$ - anti ajaib jarak. Simanjuntak (2013) kemudian menyelidiki beberapa syarat perlu bagi keberadaan graf anti ajaib jarak- $D$ yaitu untuk suatu graf terhubung yang memuat satu atau lebih cycle, graf matahari, graf prisma, graf lengkap, graf roda, graf kipas dan graf persahabatan. Tulisan ini bertujuan untuk mengkaji tentang pelabelan jarak anti ajaib pada suatu graf Petersen diperumum. Hal ini dilakukan dengan menentukan nilai $a$ yang merupakan konstanta anti ajaib dari suatu graf kemudian menyelidiki eksistensi himpunan bobot titik $\{a, a+d$, $a+2 d, \ldots, a+(n-1) d\}$. Lebih lanjut menentukan pola pelabelan titik-titik yang menghasilkan himpunan bobot titik $\{a, a+d, a+2 d, \ldots, a+(n-1) d\}$ guna merumuskan fungsi pelabelan jaraknya.

\section{HASIL DAN PEMBAHASAN}

\subsection{Pelabelan Jarak}

Suatu pelabelan berdasarkan jarak (pelabelan jarak) dikatakan pelabelan jarak anti ajaib jika bobot setiap titiknya berbeda. Pelabelan jarak anti ajaib tersebut adalah pelabelan jarak $(a, d)$-anti ajaib jika himpunan dari bobot dari 
setiap titiknya membentuk himpunan aritmatika yang progresif $\{a, a+d, a+2 d, \ldots$, $a+(n-1) d\}$. Graf yang mempunyai pelabelan $(a, d)$ anti ajaib jarak dinamakan graf anti ajaib jarak. Arumugam (2012), menyajikan beberapa hasil pelabelan $(a, d)$ anti ajaib jarak ini dalam penelitiannya.

Definisi 1 (Shafiq, dkk., 2009)

Suatu pelabelan ajaib jarak- $D$ ( $D$-distance magic labeling) pada graf $G(V, E)$ yang mempunyai orde $p$ dan ukuran $q$ adalah suatu fungsi bijektif $f: V \rightarrow\{1,2, \ldots, p\}$ dimana terdapat suatu konstanta $k$ sehingga untuk setiap titik $x \in V$ berlaku

$$
w(x)=\sum_{y \in N(x)} f(y)=k
$$

$N(x)$ adalah himpunan titik-titik yang berjarak $D$ dari $x$. Konstanta $k$ dinamakan konstanta ajaib dan $w(x)$ merupakan bobot titik $x$.

Definisi 2 (Simanjuntak, dkk., 2013)

Suatu pelabelan $(a, d)$-anti ajaib jarak-D $((a, d)$-D-distance antimagic labeling) pada graf $G(V, E)$ yang mempunyai order $p$ dan size $q$, adalah suatu fungsi bijektif $f: V \rightarrow\{1,2, \ldots, p\}$ dengan setiap titik $x \in V$ memiliki bobot $w(x)$ yang berbeda dan himpunan dari bobot tersebut dapat dinyatakan sebagai $\{a, a+d$, $a+2 d, \ldots, a+(p-1) d\}$.

Beberapa syarat perlu bagi suatu graf agar memiliki pelabelan $(a, d)$-anti ajaib jarak- $D$ dapat dilihat pada lemma-lemma berikut (Arumugam, dkk., 2012),

\section{Lemma 3}

Suatu graf yang memuat dua titik dengan $D$-tetangga yang sama bukan merupakan graf anti ajaib jarak- $D$.

\section{Lemma 4}

Misalkan $G$ suatu graf teratur- $r$. Jika $G$ adalah graf $(a, d)$-anti ajaib jarak maka

$$
d \leq r \frac{v-r}{v-1} \text { dan } a=r \frac{r(v+1)-d(v-1)}{2}
$$




\section{Akibat 5}

Diketahui $G$ suatu graf teratur-3 dengan order $p$ dan size $q$. Jika $G$ adalah graf $(a, d)$-anti ajaib jarak maka $a=p+2$ dan $d=1$.

\subsection{Pelabelan Anti Ajaib Jarak pada Graf Petersen Diperumum}

Suatu Graf $G(V, E)$ dengan order $p$ dan ukuran $q$ dinamakan Graf Petersen diperumum (generalized Petersen graph) dinotasikan $P(n, m), n \geq 3,1 \leq m<\frac{n}{2}$ jika $G$ merupakan graf kubik dengan $p=2 n$ dan $q=3 n$. Himpunan titik, $V=$ $\left\{u_{1}, \ldots, u_{n}, v_{1}, \ldots, v_{n}\right\}$ dan himpunan sisi, $E=\left\{\left\{u_{i}, u_{i+1}\right\},\left\{v_{i}, v_{i+m}\right\},\left\{u_{i}, v_{i}\right\}\right\}$ $\forall i \in\{1,2, \ldots, n\}$. Jika nilai indeks $i+1$ maupun indeks $i+m$ lebih besar dari $n$ maka nilai tersebut akan dimodulokan dengan $n$ (Ngurah, dkk., 2003).

Pelabelan anti ajaib jarak pada graf petersen diperumum akan disajikan dalam bentuk lemma berikut beserta bukti dan proses pembuktiannya. Pelabelan jarak yang dimaksud disini adalah pelabelan jarak- 1 yang selanjutnya akan ditulis sebagai pelabelan jarak saja. Bobot jarak yang dimaksud pada penelitian ini adalah bobot jarak-1 yang selanjutnya akan ditulis sebagai bobot jarak saja. Untuk menentukan pola pelabelan pada graf Petersen $P(n, 1)$, akan diselidiki pelabelan pada graf Petersen diperumum $P(3,1), P(4,1), P(5,1)$ dan $P(6,1)$.

Pada graf petersen $P(3,1)$ dengan jumlah titik $p=6$ dan jumlah sisi $q=$ 9, didefinisikan pelabelan $f$ sebagai berikut

$$
\begin{array}{ll}
f\left(u_{1}\right)=1 & f\left(v_{1}\right)=4 \\
f\left(u_{2}\right)=2 & f\left(v_{2}\right)=6 \\
f\left(u_{3}\right)=3 & f\left(v_{3}\right)=5
\end{array}
$$

diperoleh himpunan bobot dari titik-titik $P(3,1)$ adalah $\{8,9,10,11,12,13\}$ dengan $a=8$ dan $d=1$ sehingga dapat dinyatakan bahwa $P(3,1)$ merupakan graf $(8,1)$-anti ajaib jarak. Graf Petersen $P(4,1)$ yang mempunyai jumlah titik yaitu $p$ $=8$ dan jumlah sisi $q=12$ dengan pendefinisian pelabelan $f$ sebagai berikut

$$
\begin{array}{ll}
f\left(u_{1}\right)=1 & f\left(v_{1}\right)=5 \\
f\left(u_{2}\right)=2 & f\left(v_{2}\right)=8 \\
f\left(u_{3}\right)=3 & f\left(v_{3}\right)=7
\end{array}
$$




$$
f\left(u_{4}\right)=4 \quad f\left(v_{4}\right)=6
$$

diperoleh himpunan bobot dari titik-titik $P(4,1)$ adalah graf $(12,1)$-anti ajaib dengan fungsi pelabelan $f$ yang didefinisikan sebagai

$$
\begin{array}{rlrl}
f\left(u_{1}\right) & =1 & f\left(v_{1}\right) & =6 \\
f\left(u_{2}\right) & =2 & f\left(v_{2}\right) & =10 \\
f\left(u_{3}\right) & =3 & f\left(v_{3}\right) & =9 \\
f\left(u_{4}\right) & =4 & f\left(v_{4}\right)=8 \\
f\left(u_{5}\right)=5 & f\left(v_{5}\right)=7
\end{array}
$$

Graf petersen $P(6,1)$ adalah graf $(14,1)$-anti ajaib jarak.dengan fungsi pelabelan $f$ sebagai berikut

$$
\begin{array}{rlrl}
f\left(u_{1}\right)=1 & f\left(v_{1}\right)=7 \\
f\left(u_{2}\right)=2 & f\left(v_{2}\right)=12 \\
f\left(u_{3}\right)=3 & f\left(v_{3}\right)=11 \\
f\left(u_{4}\right)=4 & f\left(v_{4}\right)=10 \\
f\left(u_{5}\right)=5 & f\left(v_{5}\right)=9 \\
f\left(u_{6}\right)=6 & f\left(v_{6}\right)=8
\end{array}
$$

Untuk lebih jelas, pada Gambar 1 dapat dilihat pelabelan $(a, d)$-anti ajaib jarak pada graf Petersen $P(6,1)$.

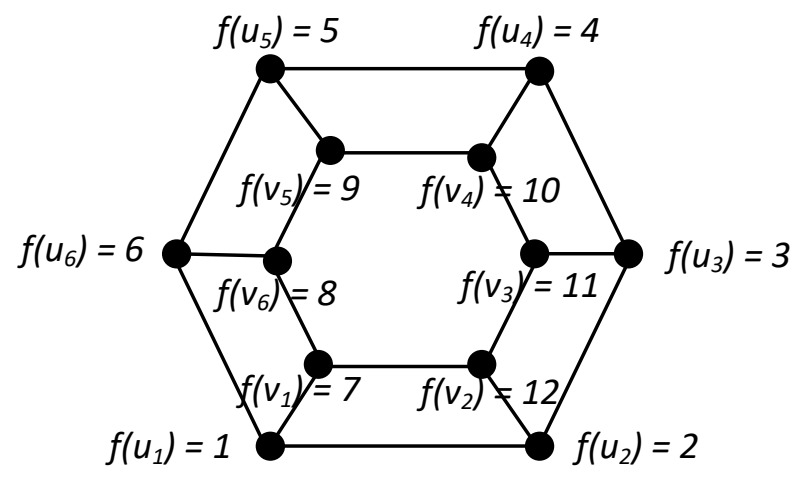

Gambar 1. Pelabelan (14,1)-Anti Ajaib Jarak pada Graf Petersen

Bobot titik-titik pada $\mathrm{P}(6,1)$ adalah

$$
\begin{array}{ll}
w\left(u_{1}\right)=15 & w\left(v_{1}\right)=21 \\
w\left(u_{2}\right)=16 & w\left(v_{2}\right)=20
\end{array}
$$




$$
\begin{array}{ll}
w\left(u_{3}\right)=17 & w\left(v_{3}\right)=25 \\
w\left(u_{4}\right)=18 & w\left(v_{4}\right)=24 \\
w\left(u_{5}\right)=19 & w\left(v_{5}\right)=23 \\
w\left(u_{6}\right)=14 & w\left(v_{6}\right)=22
\end{array}
$$

Himpunan bobot dari titik-titik $P(6,1)$ adalah $\{14,15,16,17,18,19,20$, $21,22,23,24,25\}$ yang dapat dinyatakan sebagai barisan $\{a, a+d, a+2 d, \ldots$, $a+(p-1) d\}$ dengan $a=14$ dan $d=1$ sehingga dapat dinyatakan bahwa $P(6,1)$ merupakan graf $(14,1)$-anti ajaib jarak.

Pelabelan anti ajaib pada graf Petersen $P(n, 1)$ yang mempunyai jumlah titik yaitu $p=2 n$ dan jumlah sisi $q=3 n$ akan dijelaskan melalui lemma dan akibat berikut.

\section{Lemma 6}

Graf petersen diperumum $G(V, E)=P(n, 1)$ mempunyai pelabelan $(2 \mathrm{n}+2,1)$-anti ajaib jarak

Bukti. $G(V, E)$ adalah graf petersen diperumum $P(n, 1)$ maka $V=\left\{u_{1}, u_{2}, \ldots, u_{n}\right.$ $\left.v_{1}, v_{2}, \ldots, v_{n}\right\}$ dan,$E=\left\{\left\{u_{i}, u_{i+1}\right\},\left\{v_{i}, v_{i+1}\right\},\left\{u_{i}, v_{i}\right\}\right\} \forall i \in\{1,2, \ldots, n\}$.

Pada Tabel 1, dapat dilihat bahwa setiap titik $u_{i}, v_{i} \in V$ mempunyai 3 titik yang berjarak 1 (bertetangga) dengannya.

Tabel 1. Ketetanggaan Titik-titik pada Graf Petersen $P(n, 1)$

\begin{tabular}{|c|c|c|c|}
\hline Titik & Titik tetangga 1 & Titik tetangga 2 & Titik tetangga 3 \\
\hline$u_{1}$ & $u_{n}$ & $u_{2}$ & $v_{1}$ \\
\hline$u_{2}$ & $u_{1}$ & $u_{3}$ & $v_{2}$ \\
\hline$\vdots$ & $\vdots$ & $\vdots$ & $\vdots$ \\
\hline$u_{n}$ & $u_{n-1}$ & $u_{1}$ & $v_{n}$ \\
\hline$v_{1}$ & $v_{n}$ & $v_{2}$ & $u_{1}$ \\
\hline$v_{2}$ & $v_{1}$ & $v_{3}$ & $u_{2}$ \\
\hline$\vdots$ & $\vdots$ & $\vdots$ & $\vdots$ \\
\hline$v_{n}$ & $v_{n-1}$ & $v_{1}$ & $u_{n}$ \\
\hline
\end{tabular}


Maka bobot setiap titik adalah

$$
\begin{array}{cc}
w\left(u_{1}\right)=f\left(u_{n}\right)+f\left(u_{2}\right)+f\left(v_{1}\right) & w\left(v_{1}\right)=f\left(v_{n}\right)+f\left(v_{2}\right)+f\left(u_{1}\right) \\
w\left(u_{2}\right)=f\left(u_{1}\right)+f\left(u_{3}\right)+f\left(v_{2}\right) & w\left(v_{2}\right)=f\left(v_{1}\right)+f\left(v_{3}\right)+f\left(u_{2}\right) \\
\vdots & \vdots \\
w\left(u_{n}\right)=f\left(u_{n-1}\right)+f\left(u_{1}\right)+f\left(v_{n}\right) & w\left(v_{n}\right)=f\left(v_{n-1}\right)+f\left(v_{1}\right)+f\left(u_{n}\right)
\end{array}
$$

Total bobot setiap titik pada $G$ adalah

$$
\begin{aligned}
\sum_{i=1}^{n} w\left(u_{i}\right) & =\sum_{i=1}^{n} f\left(u_{i}\right)+\sum_{i=1}^{n} f\left(v_{i}\right)+\sum_{i=1}^{n} f\left(u_{i}\right) \\
& =2 \sum_{i=1}^{n} f\left(u_{i}\right)+\sum_{i=1}^{n} f\left(v_{i}\right) \\
& =2\left(\frac{1}{2} n(2+(n-1) \cdot 1)\right)+\left(\frac{1}{2} n(2 n+2+(n-1) \cdot 1)\right) \\
& =2 n+n^{2}-n+\frac{1}{2} n(3 n+1) \\
& =n^{2}+n+\frac{3}{2} n^{2}+\frac{1}{2} n \\
& =\frac{5}{2} n^{2}+\frac{3}{2} n \\
\sum_{i=1}^{n} w\left(v_{i}\right) & =\sum_{i=1}^{n} f\left(v_{i}\right)+\sum_{i=1}^{n} f\left(u_{i}\right)+\sum_{i=1}^{n} f\left(v_{i}\right) \\
& =\sum_{i=1}^{n} f\left(u_{i}\right)+2 \sum_{i=1}^{n} f\left(v_{i}\right) \\
& =2\left(\frac{1}{2} n(2+(n-1) \cdot 1)\right)+\left(\frac{1}{2} n(2 n+2+(n-1) .1)\right) \\
= & 2 n+n^{2}-n+\frac{1}{2} n(3 n+1) \\
= & n^{2}+n+\frac{3}{2} n^{2}+\frac{1}{2} n \\
= & \frac{5}{2} n^{2}+\frac{3}{2} n \\
\sum_{i=1}^{n} & +\sum_{i=1} w\left(v_{i}\right)=\frac{5}{2} n^{2}+\frac{3}{2} n+\frac{5}{2} n^{2}+\frac{3}{2} n \\
& \\
&
\end{aligned}
$$




$$
=\frac{2 n}{2}(2(2 n+2)+(n-1) \cdot 1)
$$

Yang merupakan deret aritmatika dengan suku pertama $2 n+2$ dan beda 1 .

\section{Akibat 7}

Jika $P(n, 1)$ mempunyai pelabelan $(2 n+2,1)$-anti ajaib jarak maka pelabelan tersebut dapat didefinisikan sebagai berikut :

$$
\begin{array}{ll}
f\left(u_{i}\right)=i & \text { untuk setiap } i \in\{1,2, \cdots, n\} \\
f\left(v_{i}\right)= \begin{cases}n+i & \text { untuk setiap } i=1 \\
2 n+(2-i) & \text { untuk setiap } i \in\{2, \cdots, n\}\end{cases}
\end{array}
$$

\section{Bukti.}

Pilih pelabelan $f$, suatu fungsi bijektif dengan ketentuan sebagai berikut

$$
\begin{array}{ll}
f\left(u_{i}\right)=i & \text { untuk setiap } i \in\{1,2, \cdots, n\} \\
f\left(v_{i}\right)= \begin{cases}n+i & \text { untuk setiap } i=1 \\
2 n+2-i & \text { untuk setiap } i \in\{2, \cdots, n\}\end{cases}
\end{array}
$$
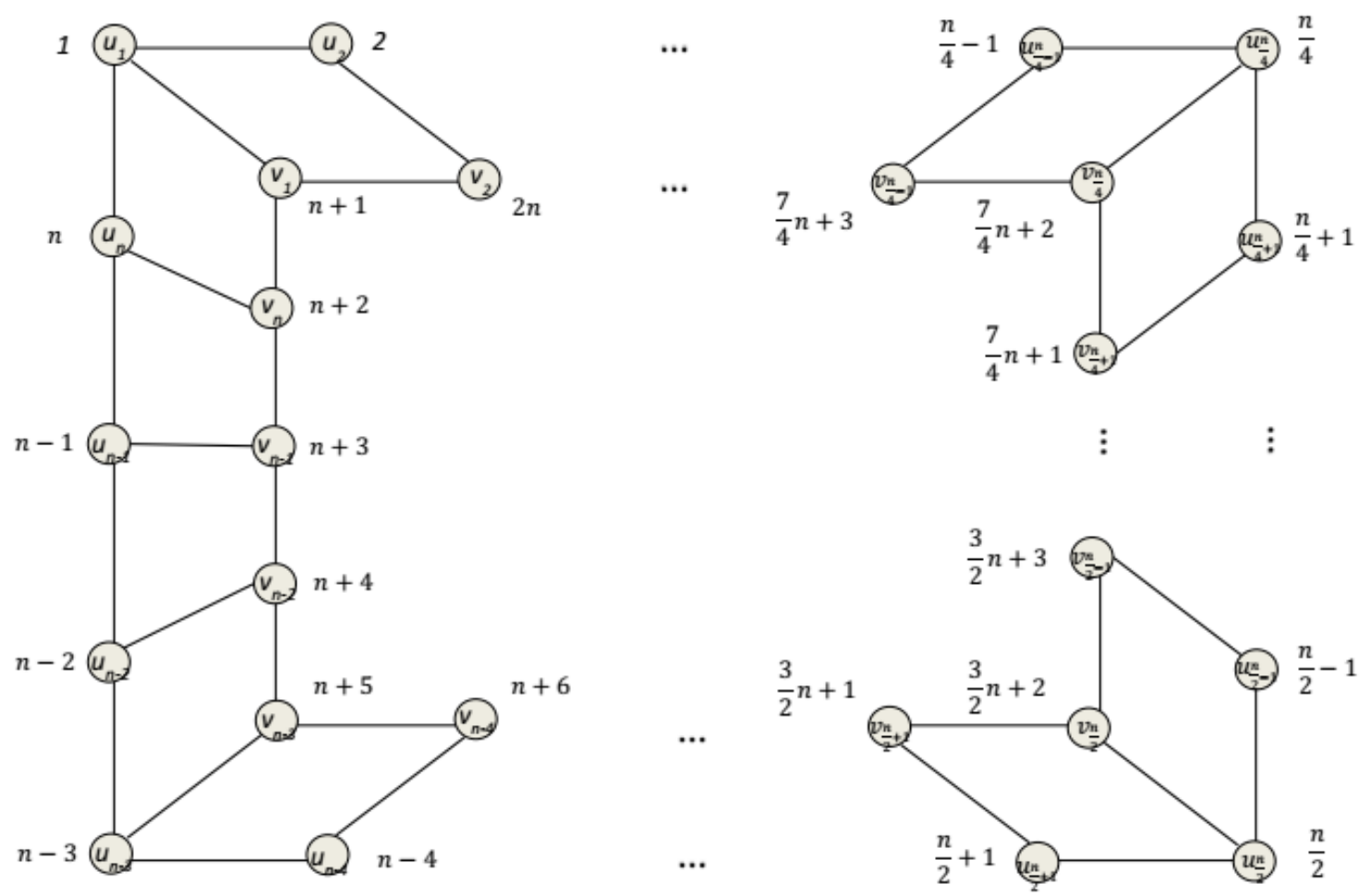

Gambar 2. Pelabelan (a, d)-Anti Ajaib Jarak Pada $P(n, 1)$

Diperoleh barisan bobot setiap titik adalah 


$$
\begin{aligned}
& w\left(u_{n}\right)=f\left(u_{n-1}\right)+f\left(u_{1}\right)+f\left(v_{n}\right)=n-1+1+n+2=2 n+2 \\
& w\left(u_{1}\right)=f\left(u_{n}\right)+f\left(u_{2}\right)+f\left(v_{1}\right)=n+2+n+1=2 n+3 \\
& w\left(u_{2}\right)=f\left(u_{1}\right)+f\left(u_{3}\right)+f\left(v_{2}\right)=1+3+2 n \quad=2 n+4 \\
& w\left(u_{n-1}\right)=f\left(u_{n-2}\right)+f\left(u_{n}\right)+f\left(v_{n-1}\right)=n-2+n+n+3=2 n+n+1 \\
& w\left(v_{2}\right)=f\left(v_{1}\right)+f\left(v_{3}\right)+f\left(u_{2}\right)=n+1+2 n-1+2=2 n+n+2 \\
& w\left(v_{1}\right)=f\left(v_{n}\right)+f\left(v_{2}\right)+f\left(u_{1}\right)=2 n+2-n+2 n+1=2 n+n+3 \\
& w\left(v_{n}\right)=f\left(v_{n-1}\right)+f\left(v_{1}\right)+f\left(u_{n}\right)=2 n+2-n+1+n+1+n=2 n+n+4 \\
& w\left(v_{n-1}\right)=f\left(v_{n-2}\right)+f\left(v_{n}\right)+f\left(u_{n-1}\right)=n+4+n+2+n-1=2 n+n+5 \\
& w\left(v_{5}\right)=f\left(v_{4}\right)+f\left(v_{6}\right)+f\left(u_{5}\right)=2 n-2+2 n-4+5=2 n+2 n-1 \\
& w\left(v_{4}\right)=f\left(v_{3}\right)+f\left(v_{5}\right)+f\left(u_{4}\right)=2 n-1+2 n-3+4=2 n+2 n+0 \\
& w\left(v_{3}\right)=f\left(v_{2}\right)+f\left(v_{4}\right)+f\left(u_{3}\right)=2 n+2 n-2+3=2 n+2 n+1
\end{aligned}
$$

Sesuai dengan Lemma. 6, bobot titik-titik pada $P(n, 1)$ dirumuskan sebagai berikut,

$$
\begin{aligned}
& w\left(u_{i}\right)= \begin{cases}2 n+2+i & \text { untuk setiap } i \in\{1,2, \cdots, n-1\} \\
2 n+2 & \text { untuk setiap } i=n\end{cases} \\
& w\left(v_{i}\right)= \begin{cases}4 n+4-i & \text { untuk setiap } i \in\{3,4, \cdots, n\} \\
3 n+4-i & \text { untuk setiap } i \in\{1,2\}\end{cases}
\end{aligned}
$$

dengan

$$
\sum_{i=1}^{n} w\left(u_{i}\right)+\sum_{i=1}^{n} w\left(v_{i}\right)=\frac{2 n}{2}(2(2 n+2)+(n-1) \cdot 1) .
$$

Sebagai penutup dari paper ini, disampaikan sebuah konjektur sebagai bahan penelitian lebih lanjut.

\section{Konjektur 8}

Setiap graf petersen diperumum $P(n, m)$ mempunyai pelabelan $(a, d)$-anti ajaib jarak untuk nilai $n$ dan $m$ tertentu. 


\section{KESIMPULAN DAN SARAN}

Dari pembahasan diatas, dapat disimpulkan bahwa graf Petersen diperumum $P(n, 1)$ yang merupakan suatu graf teratur berderajat 3 dengan jumlah titik $2 n$, jumlah sisi $2 n$ merupakan graf anti ajaib jarak dan mempunyai pelabelan $(2 n+2,1)$-anti ajaib jarak. Walaupun baru berdasarkan dugaan (counting argument), graf Petersen diperumum $P(n, 2)$ juga merupakan $(2 n+2,1)$-anti ajaib jarak dan diharapkan dapat memjadi bahan untuk penelitian lebih lanjut.

\section{DAFTAR PUSTAKA}

Arumugam, S., Froncek, D., Kamatchi, N., Distance Magic Graphs-A Survey, J. Indones. Math. Soc. Special Edition (2011), 11-26.

Arumugam, S., Kamatchi, N., On (a;d)-Distance Antimagic Graphs, Australasian J. Combinat. 54 (2012), 279-287.

Beena, S., On $\Sigma$ and $\Sigma$ ' Labelled Graphs, Discrete Math., 309 (2009), 1783-1787.

Griggs, R. Yeh, K., Labelling Graphs with a Condition at Distance 2, Siam J. Discrete Math. 4 (1992), 586-595.

Kovar, P., Froncek, D., Kovarova, T., A Note on 4-Regular Distance Magic Graphs, Australasian J. Combinat. 54 (2012), 127-132.

Miller, M., Simanjuntak, R., Distance Magic Labelings of Graphs, Australasian J. Combinat. 28 (2003), $305-315$.

Ngurah, A.A.G., Baskoro, E.T., On Magic and Antimagic Total Labeling of Generalized Petersen Graph. Utilitas Math. 63 (2003), 97-107.

O'neal, A., Slater, P. J., Uniqueness Of Vertex Magic Constants, Siam J. Discrete Math., 27(2) (2013), No. 2, 708-716, 2013.

Shafiq, M.K., Ali, G., Simanjuntak, R., Distance Magic Labeling of a Union Graphs, AKCE J. Graphs Combinat. 6 (1) (2009), 191-200.

Simanjuntak, R., Elviyenti, M., Jauhari, M. N., Praja, A.S., Purwasih, I.A., Magic Labelings of Distance at Most 2, 37th Australasian Conference on Combinatorial Mathematics and Combinatorial Computing, arXiv:1312.7633 [math.CO], 2013. 
Simanjuntak, R., Wijaya, K., On Distance Antimagic Graphs, ArXiv 1312 [Math.CO] 28 Dec.2013, 2013. 